\title{
ICE-SHEET TOPOGRAPHY FROM GEOSAT RADAR ALTIMETRY \\ (Abstract)
}

by

H. Jay Zwally and R.A. Bindschadler

(Oceans and Ice Branch, Code 671, NASA / Goddard Space Flight Center, Greenbelt, MD 20771, U.S.A.)

\begin{abstract}
Ice-sheet surface topography is the principal ice parameter obtainable from satellite radar altimetry. Surface-elevation maps of the East Antarctic ice sheet north of $72^{\circ} \mathrm{S}$ from Seasat data, collected between July and October 1978, and preliminary maps from Geosat data, collected between March 1985 and September 1986, are described. The Geosat data, obtained from the U.S. Navy as an unclassified data set, have greatly increased the density of elevation measurements. A principal correction to the altimeter measurements is obtained by applying a computer curve-fitting procedure to each radar waveform to correct for errors in the automatic range-tracking circuitry of the altimeter. The errors are caused by slow response to range variations due to undulations of the ice surface between
\end{abstract}

successive measurements made at intervals of $662 \mathrm{~m}$ along track. The retracking correction for Geosat data has a standard deviation of $2.4 \mathrm{~m}$ and a mean value of $1.1 \mathrm{~m}$, values which are about $20 \%$ smaller than the corresponding values for Seasat. The positive mean correction indicates a common tendency of the altimeters' automatic tracking to give an excessive range to the surface. The precision of the measurements, given by the standard deviation of the range differences at cross-over points, is about $1.6 \mathrm{~m}$ before adjustment for errors in the radial position of the satellite orbit. The preliminary surface-elevation maps from Geosat data are improved over those produced from Seasat, mainly due to optimal spacing of successive ground tracks. The locations of ice divides and drainage basins along the East Antarctic coast are delineated by several methods, including vector plots of surface slope. 